\title{
Isolation, biochemical characterization and antibiotic profiling of members of Enterobacteriacea isolated from animal fecal matter
}

\author{
Azra Rashid \\ Department of Microbiology, Sardar Bhagwan Singh PG Institute of Biomedical Sciences and Research, \\ Affiliated to HNB Garwal University, Dehradun, India
}

\begin{abstract}
In the present study, fecal samples were collected from different localities of Balawala, Dehradun city. Out of 87 isolates, 50\% were E. coli, 25\% were Klebsiella spp., 15\% were Enterobacteriaceae spp. and 10\% were Proteus spp. The isolates were then checked for antibiotic sensitivity. 50\% strains were resistant for novabiocin, 25\% were resistant for cefixime, 15\% were resistant for clotrimazole and 10\% were resistant for amoxicillin and most of these showed sensitivity against the antibiotics- Amikacin, amoxicillin, cefixime, cephalexin, ciprofloxacin, clotrimazole, gentamicin, novabiocin, ofloxacin and trimethoprim. In the minimum inhibitory concentration test, $50 \%$ of the isolates showed resistance against the antibiotics amoxicillin, ampicillin, streptomycin at different concentrations $(8 \mu \mathrm{g} / \mathrm{ml}, 16 \mu \mathrm{g} / \mathrm{ml}, 32 \mu \mathrm{g} /$ $\mathrm{ml}, 64 \mu \mathrm{g} / \mathrm{ml}$ and $128 \mu \mathrm{g} / \mathrm{ml}$ respectuvely) and 50\% showed sensitivity against the antibiotics cefoparazone sulbactum, meropenem and piperacillin tazobactum. In conclusion, the data of the present study determine the resistance profile of enteric pathogens in animal fecal samples and is helpful from the community infection point of view. The study provides some insight on the prevalence dynamics of enteric pathogens from animal fecal which can be helpful to clinicians to formulate proper antimicrobial therapy.
\end{abstract}

KEY WORDS: AMIKACIN, RESISTANCE PROFILE, MINNIMUM INHIBITORY CONCENTRATION, MRSA, ENTEROBACTERIACEA

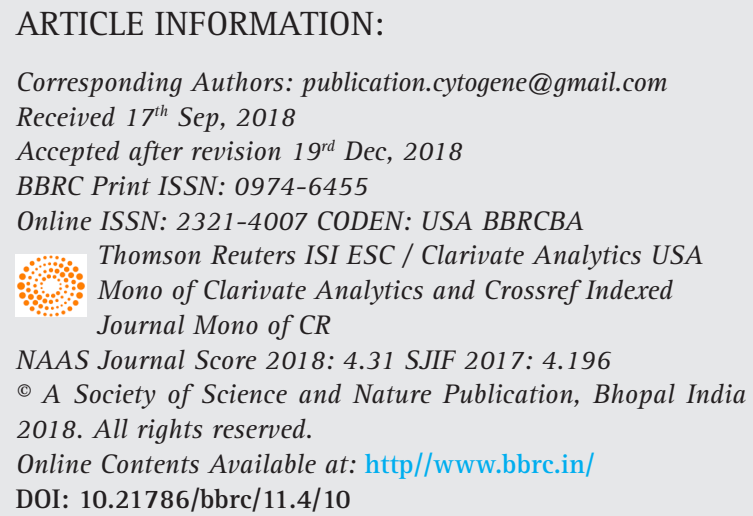




\section{INTRODUCTION}

Bacterial resistance to antibiotics continues to curb our ability to treat, cure and control infectious diseases. Two organisms in particular that have become major public health threats are methicillin-resistant Staphylococcus aureus and penicillin-resistant Streptococcus pneumoniae. Resistance to aminocyclitol aminoglycosides is an important clinical problem since these antibiotics are widely used in the treatment of serious infections, (Larson et al., 1986; Garcia et al., 1989). Large quantities of enteric bacteria from animal fecal wastes can be released into rivers and lakes that serve as sources of water for drinking, recreation or irrigation. Fecal contamination is considered to be main contributor of enteric pathogens to natural water sources. Infection originating from such sources specially diarrhea and typhoid fever. The family of Enetrobacteriaceae is accountable for these illnesses. The important members of Enterobacteriaceae are E. coli, Salmonella and Shigella. Amikacin has been the drug of choice for treating nosocomial infections refractory to other aminoglycosides (Gerding et al., 1990; Levine et al., 1985, Kalita et al., 2016).

In recent years, resistance to amikacin due to production of 3'-aminoglycoside-phosphotransferases, 2" -adenyltransferases and aminoglycoside-6'- N-acetyltransferases has been reported (Hopkins et al., 1991; Shaw et al., 1993; Shimizu et al., 1985). Transmission of this microbe is usually through uncooked meats and eggs. The disease is spread via the fecal-oral route and requires very low cell numbers to initiate infection. In many cases, Shigella infection will lead to diarrhea accompanied by fever. Among the disease caused by poultry and other farms and their products some are often severe and sometimes lethal infection such as meningitis, endocarditis, urinary tract infections, septecimia, epidemic diarrhea of adults and children. Resistance are more commonly observed among isolates of animal fecal. The relatively intensive conditions under which animal are housed may be associated with greater disease potential and therefore a greater potential and therefore a greater tendency for antibiotic use of disease control (Bywater et al., 2004).

Resistance to antimicrobials and particularly multidrug resistance is an emerging problem in Enterobacteriaceae for developing and developed countries (Schwarz and White, 2005). Resistant microorganisms have emerged as a result of improper use of antibiotics in human health as well as in agricultural practices (Khachatourians, 1998). Investigators have reported evidence of some low-level resistance to antibiotics, but overall the bacteria studied were sensitive to most antibiotics prior to exposure (Datta and Hughes, 1983; Dancer, 1997).

\section{MATERIALS AND METHODS}

Isolation of Enteric Pathogens: Sample was diluted appropriately in sterile saline by serial dilution method and then an appropriate dilution $(0.1 \mathrm{ml})$ was plated on selective media and incubated at $37{ }^{\circ} \mathrm{C}$ for 24 to $48 \mathrm{~h}$ (Pelcezar et al., 1986) and then observed for the growth.

Identification and characterization of Enteric pathogens: All suspected colonies on respective selective media were presumptive forms identified using identification scheme of Bergey's manual (1997) that identifies bacteria on the basis of morphological, cultural and biochemical characteristics. The methods suggested in the microbiological methods were followed (Borrego and Figueras, 1997) for characterization of the bacterial isolates.

Antibiotic Susceptibility Test: Bacterial isolates viz., E. coli, Enterobacteriaceae, Klebsiella sps., Proteus sps. were screened for their sensitivity to antibiotics because the frequency of occurrence of these pathogens was very high. Multidrug resistant strains of these pathogens are emerging worldwide. Overnight growth of respective bacterial isolates was used for the sensitivity test. The Kirby Bauer modified disk diffusion technique was was used to determine the sensitivitity to antibiotics.The polydiscs (Micromaster Laboratories) were evenly distributed on sterile Mueller Hinton agar medium. Plates were then incubated at $37{ }^{\circ} \mathrm{C}$ for $24 \mathrm{~h}$. The inhibition zone diameters were measured using meter scale. Inhibition zone diameters were compared with the standard inhibition zone for resistance, intermediate and susceptible character (Kalita et al., 2016).

Minimal Inhibitory Concentration (MIC): Minimum inhibitory concentration was determined according to the method described earlier by adding various concentrations of antibiotics $(8-128 \mu \mathrm{g} / \mathrm{ml})$ in Nutrient Broth. Further, $100 \mu \mathrm{l}$ of inoculum was added to each tube and incubated the tubes at $37^{\circ} \mathrm{C}$ for 24 hours (Sharma et al., 2011).

\section{RESULTS AND DISCUSSION}

Isolation of Enteric pathogens from Animal excreta Samples of animals were collected aseptically and transported to the laboratory immediately for isolation of enteric pathogens on Mac-Conkey agar, Eosine methylene agar, Cystine-lactose-electrolyte-deficient agar plates. The plates were incubated for 14- 16 hours at $37^{\circ} \mathrm{C}$ and after incubation observations were made there are appearances of isolated colonies. The isolated colonies were further pure cultured by sub-streaking on Mac-Conkey agar plates (shown in Fig. 1). The culture 


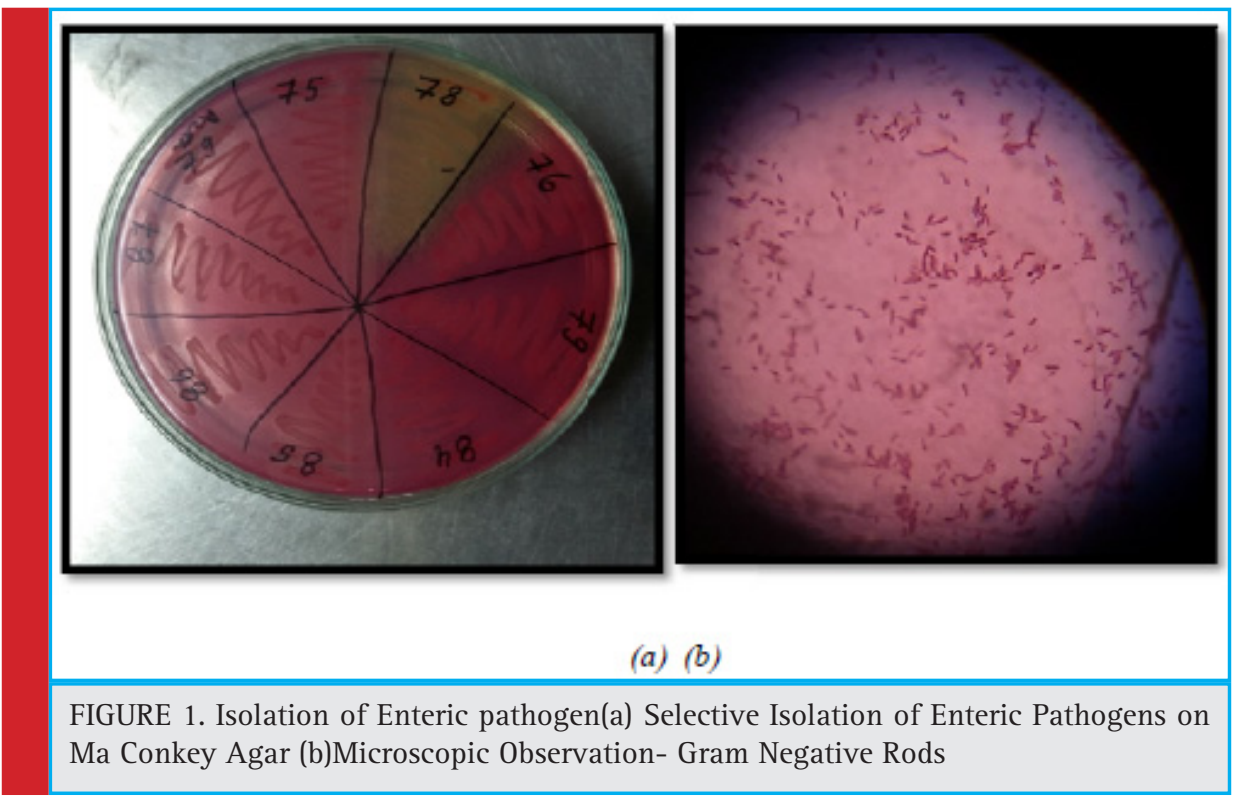

thus obtained and the details of healthy animals and humans are given in Table 1

In this study susceptibility pattern of pathogens liable for urinary tract infections in Poland to cogently used antimicrobial agents. A most entire study of 141 pathogens from hospital - acquired infections and 460 pathogens from community- acquired infections were isolated between July 1998 and May 1999. The most common ecological agent was E. coli (73.0 \%), followed by Proteus spp. (8.9\%) and other species of Enterobacteriaceae $(9.6 \%)$. Few community infections were caused by Gram-positive cocci were isolated more frequently from a hospital setting $(14.1 \%)$ and the most common was Enterococcus spp. (8.5\%). Pseudomonas aeruginosa was found only among hospital isolates and was responsible for $10.7 \%$ of infections. E.coli isolates from both community and hospital infections were highly affected to many antimicrobial agents with the explusion of those isolates generating elongated spectrum beta- lactamases (ESBLs). Of all Enterobacteriaceae tested, 38 strains (6.9 \%) were able to generating ESBLs (Ahmed et al., 2011).

\section{ANTIBIOTIC SENSITIVITY TEST}

Antibiotic sensitivity of all the 87 isolates was determined against 10 antibiotics belonging to $\beta$-lactam and non $\beta$-lactam group. The antibiotics included are Amikacin, Amoxycillin, Cefixime, Cephalexin, Ciprofloxacin, Clotrimazole, Gentamycin, Kanamycin, Novabiocin and Ofloxacin. There sensitivity to different antibiotics is represented in Graph 1, 2 \&t 3.

According to Ergin \& Mutlu, 197 bacterial isolates from Sudanese patients with diarrhea or urinary tract infections. Shigella dysenteriae type 1 and enteropatho- genic E. coli Showed high resistance rates against the commonly used antimicrobial agents: ampicillin, chloramphenocol, amoxycillin, co-trimoxazole, tetracycline, malidixic acid, sulfonamide and neomycin. The uropathogens wre completely sensitive to ciprofloxacin. Resistance to tetracycline, amoxicillin, ampicillin, cotrimoxazole and sulfonamide was the most frequent pattern. The common urinary tract pathogens Klebsiella pneumonia, E. coli and Proteus mirabilis showed high rates of resistance to ampicilin, co-trimoxazole, amoxicillin, tetracycline, trimethoprim, sulfonamide, streptomycin and carbenicillin.

\section{MINIMUM INHIBITORY CONCENTRATION}

Of all 87 samples 25 samples were selected for carrying out MIC of Amoxycillin, Ampicillin, Pipracillin tazobactum, Streptomycin, Meropenem and Cefoparazone sulbactum. The MIC was conducted at different concentrations like $(8 \mu \mathrm{g}, 16 \mu \mathrm{g}, 32 \mu \mathrm{g}, 64 \mu \mathrm{g}$ and $128 \mu \mathrm{g})$. Maximum isolates showed resistance against Amoxycillin and minimum against Meropenem and Cefoparazone sulbactum. In decresing order of resistance antibiotics can be placed as Amoxycillin>Ampicillin>Streptomycin $>$ Pipracillintazobactum $>$ Meropenem $>$ Cefoparazone sulbactum. The MIC result of isolates is shown in Graph. 4, 5, 6 \&t 7 .

In this study they determined the distribution rates of Pseudomonas aeuroginosa in clinics and its resistance to antibiotics. The antibiotic resistance rates were detected by minimal inhibitory concentration (MIC). The clinical and specimen distribution properties of Pseudomonas were evaluated based on their resistance pattern. Pseudomonas was the fourth common bacteria in all isolates. 
Table 1. Cultures obtained from Animal Fecal Matter

\begin{tabular}{|c|c|c|c|c|}
\hline S. No & Sample Number & Growth On MacConkey Agar & Morphology & Motility \\
\hline 1. & $\mathrm{AH} 1$ & Small pink color colonies/ pink background & Small pink color colonies and mucoid & $+\mathrm{ve}$ \\
\hline 2. & $\mathrm{AH} 2$ & Pink color colonies/ pink background & Small pink color colonies and mucoid & $+\mathrm{ve}$ \\
\hline 3. & AH3 & Pink color colnies/ pink background & Small pink color colonies and mucoid & -ve \\
\hline 4. & $\mathrm{AH} 4$ & Pink color colonies/ pink background & Small pink color colonies and mucoid & -ve \\
\hline 5. & AH5 & Pink color colonies/ pink background & Small pink color colonies and mucoid & $+\mathrm{ve}$ \\
\hline 6. & AH6 & Pink color colonies/ pink background & Small pink color colonies and mucoid & -ve \\
\hline 7. & AH7 & Pink color colonies/ pink background & Small pink color colonies and mucoid & $+\mathrm{ve}$ \\
\hline 8. & AH8 & Pink color colonies/ pink background & Small pink color colonies and mucoid & $+\mathrm{ve}$ \\
\hline 9. & AH9 & Pink color colonies/ pink background & Small pink color colonies and mucoid & -ve \\
\hline 10. & $\mathrm{AH} 10$ & Yellow swarming colonies/ yellow background & Yellow color colony and show motility & $+\mathrm{ve}$ \\
\hline 11. & AH11 & Small pink color colonies/ pink background & Small pink color colonies and mucoid & $+\mathrm{ve}$ \\
\hline 12. & AH12 & Pink color colonies/ pink background & Small pink color colonies and mucoid & $+\mathrm{ve}$ \\
\hline 13. & $\mathrm{AH} 13$ & Pink color colonies/ pink background & Small pink color colonies and mucoid & $+\mathrm{ve}$ \\
\hline 14. & AH14 & Pink color colonies/ pink background & Small pink color colonies and mucoid & $+\mathrm{ve}$ \\
\hline 15. & AH15 & Yellow color colonies/ yellow background & Gram -ve, non-motile and rod shaped & -ve \\
\hline 16. & AH16 & Colorless colonies/ white background & Gram -ve, non-motile and rod shaped & $+\mathrm{ve}$ \\
\hline 17. & AH17 & Pink color colonies/ pink background & Small pink color colonies and mucoid & $+\mathrm{ve}$ \\
\hline 18. & AH18 & Pink color colonies/ pink background & Small pink color colonies and mucoid & $+\mathrm{ve}$ \\
\hline 19. & AH19 & Translucent gummy colonies/ pink background & Gram -ve, non-motile and rod shaped & $+\mathrm{ve}$ \\
\hline 20. & $\mathrm{AH} 20$ & Colorless colonies/ pink background & Gram -ve, non-motile and rod shaped & $+\mathrm{ve}$ \\
\hline 21. & $\mathrm{AH} 21$ & Pink color colonies/ pink background & Small pink color colonies and mucoid & $+\mathrm{ve}$ \\
\hline 22. & $\mathrm{AH} 22$ & Pink color colonies/ pink background & Small pink color colonies and mucoid & -ve \\
\hline 23. & $\mathrm{AH} 23$ & Translucent gummy colonies/ pink background & Gram -ve, non-motile and rod shaped & $+\mathrm{ve}$ \\
\hline 24. & $\mathrm{AH} 24$ & Colorless colonies/ pink background & Gram -ve, non-motile and rod shaped & +ve \\
\hline 25. & $\mathrm{AH} 25$ & Yellowish gummy colonies/ yellow background & Gram -ve, non-motile and rod shaped & -ve \\
\hline 26. & $\mathrm{AH} 26$ & Colorless colonies/ white background & Gram -ve, non-motile and rod shaped & $+\mathrm{ve}$ \\
\hline 27. & AH27 & Colorless colonies/ white background & Gram -ve, non-motile and rod shaped & $+\mathrm{ve}$ \\
\hline 28. & $\mathrm{AH} 28$ & Pink color colonies/ pink background & Small pink color colonies and mucoid & $+\mathrm{ve}$ \\
\hline 29. & $\mathrm{AH} 29$ & Pink color colonies/ pink background & Small pink color colonies and mucoid & +ve \\
\hline 30. & $\mathrm{AH} 30$ & Pink color colonies/ pink background & Small pink color colonies and mucoid & $+\mathrm{ve}$ \\
\hline 31. & $\mathrm{AH} 31$ & Pink color colonies/ pink background & Small pink color colonies and mucoid & $+\mathrm{ve}$ \\
\hline 32. & АН32 & Pink color colonies/ pink background & Small pink color colonies and mucoid & $+\mathrm{ve}$ \\
\hline 33. & АН33 & Pink color colonies/ pink background & Small pink color colonies and mucoid & +ve \\
\hline 34. & $\mathrm{AH} 34$ & Pink color colonies/ pink background & Small pink color colonies and mucoid & -ve \\
\hline 35. & AH35 & Colorless colonies/ pink background & Gram -ve, non-motile and rod shaped & $+\mathrm{ve}$ \\
\hline 36. & AH36 & Pink color colonies/ pink background & Small pink color colonies and mucoid & $+\mathrm{ve}$ \\
\hline 37. & AH37 & Pink color colonies/ pink background & Small pink color colonies and mucoid & +ve \\
\hline 38. & АH38 & Pink color colonies/ pink background & Small pink color colonies and mucoid & +ve \\
\hline 39. & АH39 & Pink color colonies/ pink background & Small pink color colonies and mucoid & -ve \\
\hline 40. & $\mathrm{AH} 40$ & Pink color colonies/ pink background & Small pink color colonies and mucoid & +ve \\
\hline 41. & $\mathrm{AH} 41$ & Pink color colonies/ pink background & Small pink color colonies and mucoid & $+\mathrm{ve}$ \\
\hline 42. & $\mathrm{AH} 42$ & Pink color colonies/ pink background & Small pink color colonies and mucoid & +ve \\
\hline 43. & $\mathrm{AH} 43$ & Colorless colonies/ pink background & Gram -ve, non-motile and rod shaped & $+\mathrm{ve}$ \\
\hline 44. & AH44 & Pink color colonies/ pink background & Small pink color colonies and mucoid & +ve \\
\hline
\end{tabular}




\begin{tabular}{|c|c|c|c|c|}
\hline 44. & AH44 & Pink color colonies/ pink background & Small pink color colonies and mucoid & +ve \\
\hline 45. & AH45 & Colorless colonies/ pink background & Gram -ve, non-motile and rod shaped & + ve \\
\hline 46. & $\mathrm{AH} 46$ & Colorless colonies/ pink background & Gram -ve, non-motile and rod shaped & -ve \\
\hline 47. & $\mathrm{AH} 47$ & Translucent gummy colonies/ pink background & Gram -ve, non-motile and rod shaped & +ve \\
\hline 48. & AH48 & Pink color colonies/ pink background & Small pink color colonies and mucoid & +ve \\
\hline 49. & AH49 & Small orange color colonies/ pink background & Gram -ve, non-motile and rod shaped & +ve \\
\hline 50. & AH50 & Pink color colonies/ pink background & Small pink color colonies and mucoid & +ve \\
\hline 51. & AH51 & Colorless colonies/ pink background & Gram -ve, non-motile and rod shaped & $+\mathrm{ve}$ \\
\hline 52. & AH52 & Pink color colonies/ pink background & Small pink color colonies and mucoid & -ve \\
\hline 53. & AH53 & Pink color colonies/ pink background & Small pink color colonies and mucoid & + ve \\
\hline 54. & AH54 & Pink color colonies/ pink background & Small pink color colonies and mucoid & +ve \\
\hline 55. & AH55 & Translucent gummy colonies/ pink background & Gram -ve, non-motile and rod shaped & + ve \\
\hline 56. & AH56 & Pink color colonies/ pink background & Small pink color colonies and mucoid & +ve \\
\hline 57. & AH57 & Translucent gummy colonies/ pink background & Gram -ve, non-motile and rod shaped & + ve \\
\hline 58. & AH58 & Colorless colonies/ pink background & Gram -ve, non-motile and rod shaped & +ve \\
\hline 59. & AH59 & Pink color colonies/ pink background & Small pink color colonies and mucoid & +ve \\
\hline 60. & AH60 & Colorless colonies/ pink background & Gram -ve, non-motile and rod shaped & -ve \\
\hline 61. & AH61 & Pink color colonies/ pink background & Small pink color colonies and mucoid & +ve \\
\hline 62. & AH62 & Yellow swarming colonies/ yellow background & Yellow color colony and show motility & +ve \\
\hline 63. & AH63 & Pink color colonies/ pink background & Small pink color colonies and mucoid & +ve \\
\hline 64. & AH64 & Colorless colonies/ pink background & Gram -ve, non-motile and rod shaped & -ve \\
\hline 65. & AH65 & Pink color colonies/ pink background & Small pink color colonies and mucoid & + ve \\
\hline 66. & AH66 & Pink color colonies/ pink background & Small pink color colonies and mucoid & + ve \\
\hline 67. & AH67 & Yellow swarming colonies/ yellow background & Yellow color colony and show motility & +ve \\
\hline 68. & AH68 & Pink color colonies/ pink background & Small pink color colonies and mucoid & $+\mathrm{ve}$ \\
\hline 69. & AH69 & Colorless colonies/ pink background & Gram -ve, non-motile and rod shaped & +ve \\
\hline 70. & AH70 & Translucent gummy colonies/ white background & Gram -ve, non-motile and rod shaped & +ve \\
\hline 71. & AH71 & Pink color colonies/ pink background & Small pink color colonies and mucoid & $+\mathrm{ve}$ \\
\hline 72. & AH72 & Pink color colonies/ pink background & Small pink color colonies and mucoid & $+\mathrm{ve}$ \\
\hline 73. & AH73 & Pink color colonies/ pink background & Small pink color colonies and mucoid & $+\mathrm{ve}$ \\
\hline 74. & AH74 & Pink color colonies/ pink background & Small pink color colonies and mucoid & $+\mathrm{ve}$ \\
\hline 75. & AH75 & Pink color colonies/ pink background & Small pink color colonies and mucoid & $+\mathrm{ve}$ \\
\hline 76. & AH76 & Pink color colonies/ pink background & Small pink color colonies and mucoid & $+\mathrm{ve}$ \\
\hline 77. & AH77 & Pink color colonies/ pink background & Small pink color colonies and mucoid & $+\mathrm{ve}$ \\
\hline 78. & AH78 & Translucent gummy colonies/ yellow background & Gram -ve, non-motile and rod shaped & $+\mathrm{ve}$ \\
\hline 79. & AH79 & Pink color colonies/ pink background & Small pink color colonies and mucoid & $+\mathrm{ve}$ \\
\hline 80. & AH80 & Pink color colonies/ pink background & Small pink color colonies and mucoid & $+\mathrm{ve}$ \\
\hline 81. & AH81 & Pink color colonies/ pink background & Small pink color colonies and mucoid & $+\mathrm{ve}$ \\
\hline 82. & AH82 & Pink color colonies/ white background & Small pink color colonies and mucoid & $+\mathrm{ve}$ \\
\hline 83. & AH83 & Colorless colonies/ white background & Gram -ve, non-motile and rod shaped & $+\mathrm{ve}$ \\
\hline 84. & AH84 & Pink color colonies/ pink background & Small pink color colonies and mucoid & $+\mathrm{ve}$ \\
\hline 85. & AH85 & Pink color colonies/ pink background & Small pink color colonies and mucoid & $+\mathrm{ve}$ \\
\hline 86. & AH86 & Pink color colonies/ pink background & Small pink color colonies and mucoid & $+\mathrm{ve}$ \\
\hline 87. & AH87 & Pink color colonies/ pink background & Small pink color colonies and mucoid & +ve \\
\hline
\end{tabular}



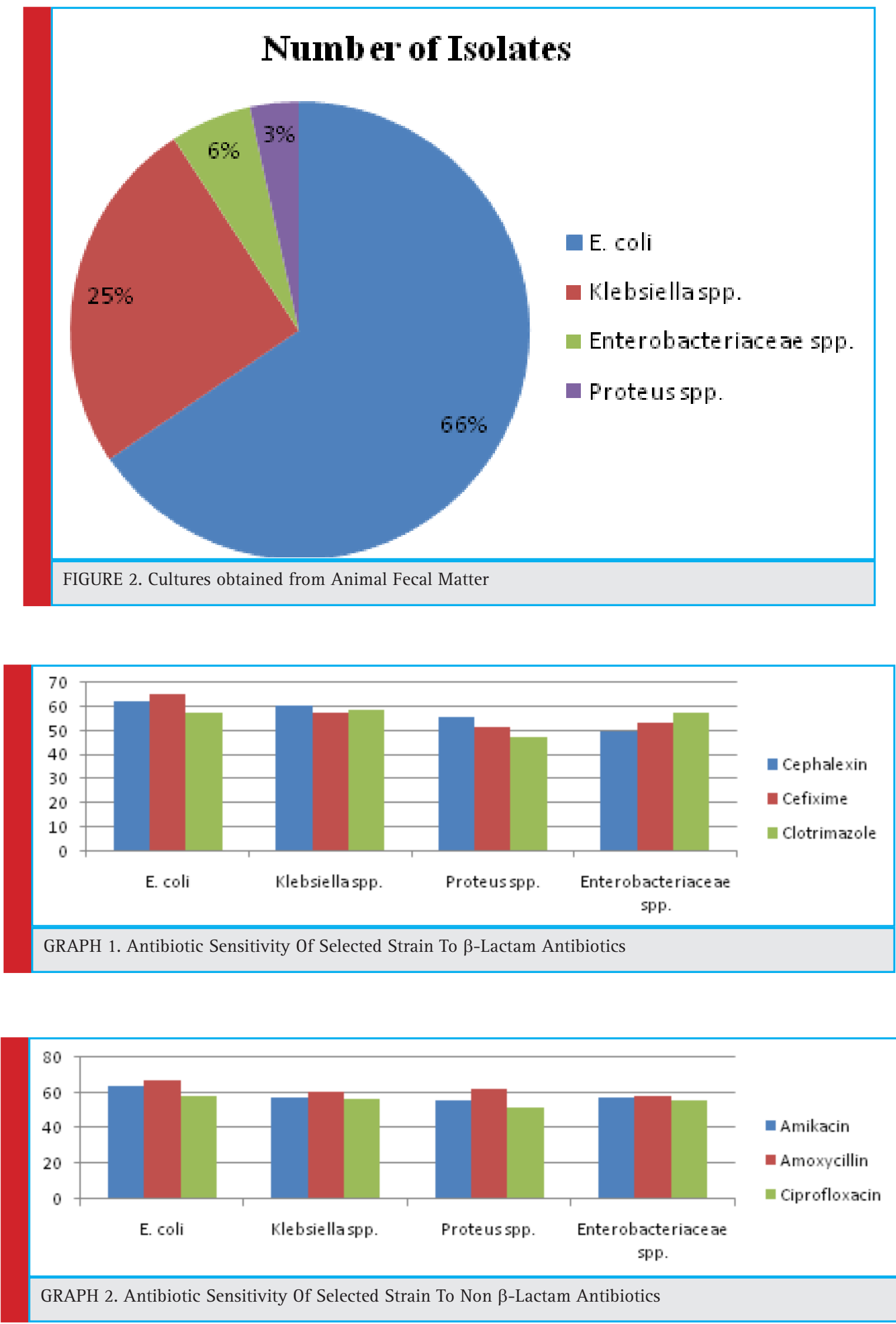

608 ISOLATION, BIOCHEMICAL CHARACTERIZATION AND ANTIBIOTIC PROFLING OF MEMBERS 

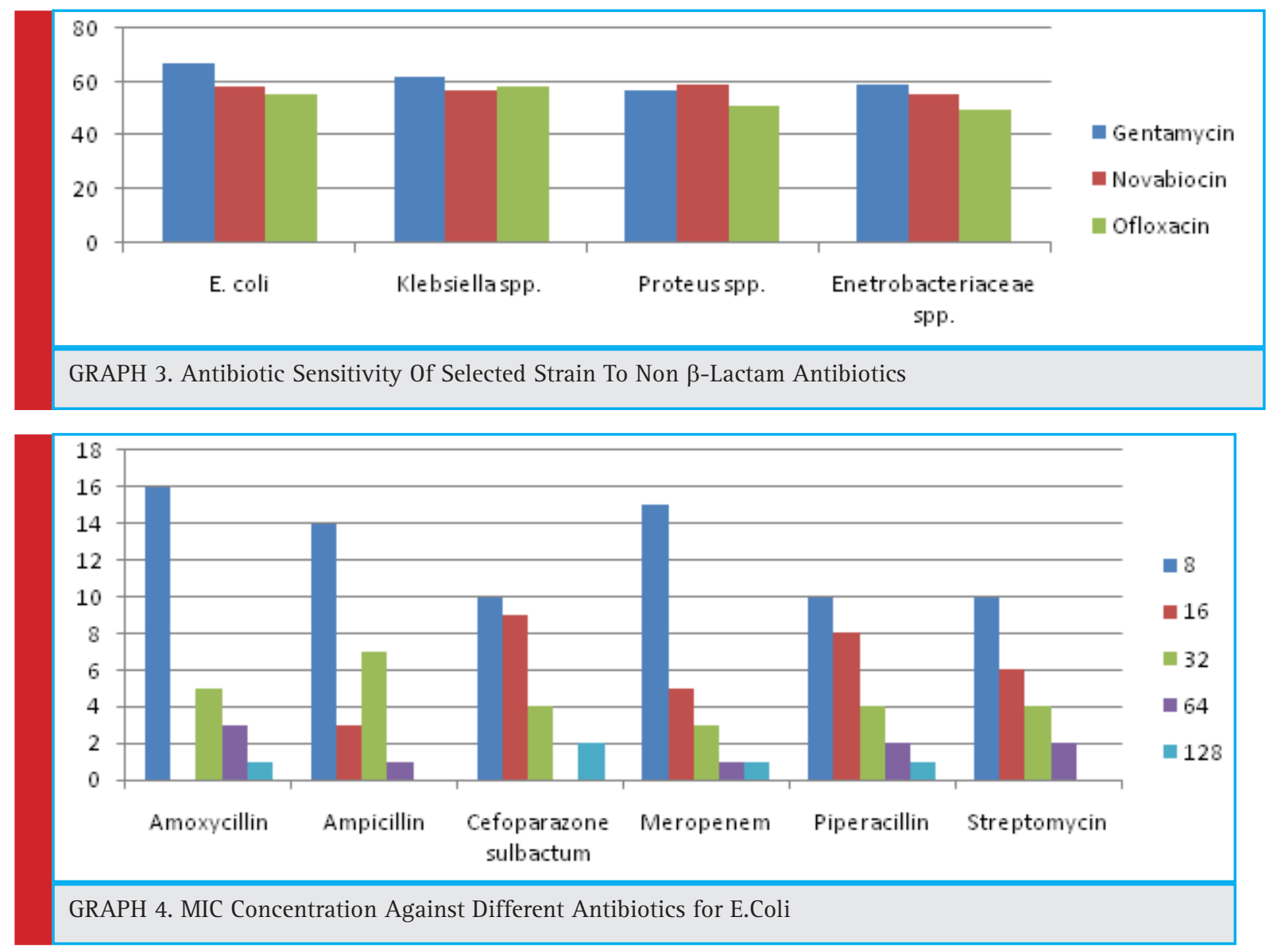

Tracheal aspirates, sputum and wound, pus were important sources for Pseudomonas aeruginosa isolation in intensive and nonintensive care units of surgery wards (SW-ICU, SW-nonICU) $(\mathrm{p}<0.05)$. on the basis of MIC criteria, the resistance ratios of the isolates to cefriaxone, cefotaxime, ceftazidime, imipenem, ofloxacin and ciprofloxacin were 8.4\%,15.0\%, 13.3\%, 0.0\%, $11.6 \%$ and 8.3\% respectively (Hryniewicz et al., 2001).
A wide range of pathogenic microorganisms can be transmitted to humans via water contaminated with fecal matter. These include enteropathogenic agents such as E. coli, Shigella, salmonella, enteroviruses and multicellular parasites as well as opportunistic pathogens like Pseudomonas aeruginosa, Klebsiella etc. Applications of antibiotics bring about an increase in resistance to antibiotics not only in pathogenic bacterial

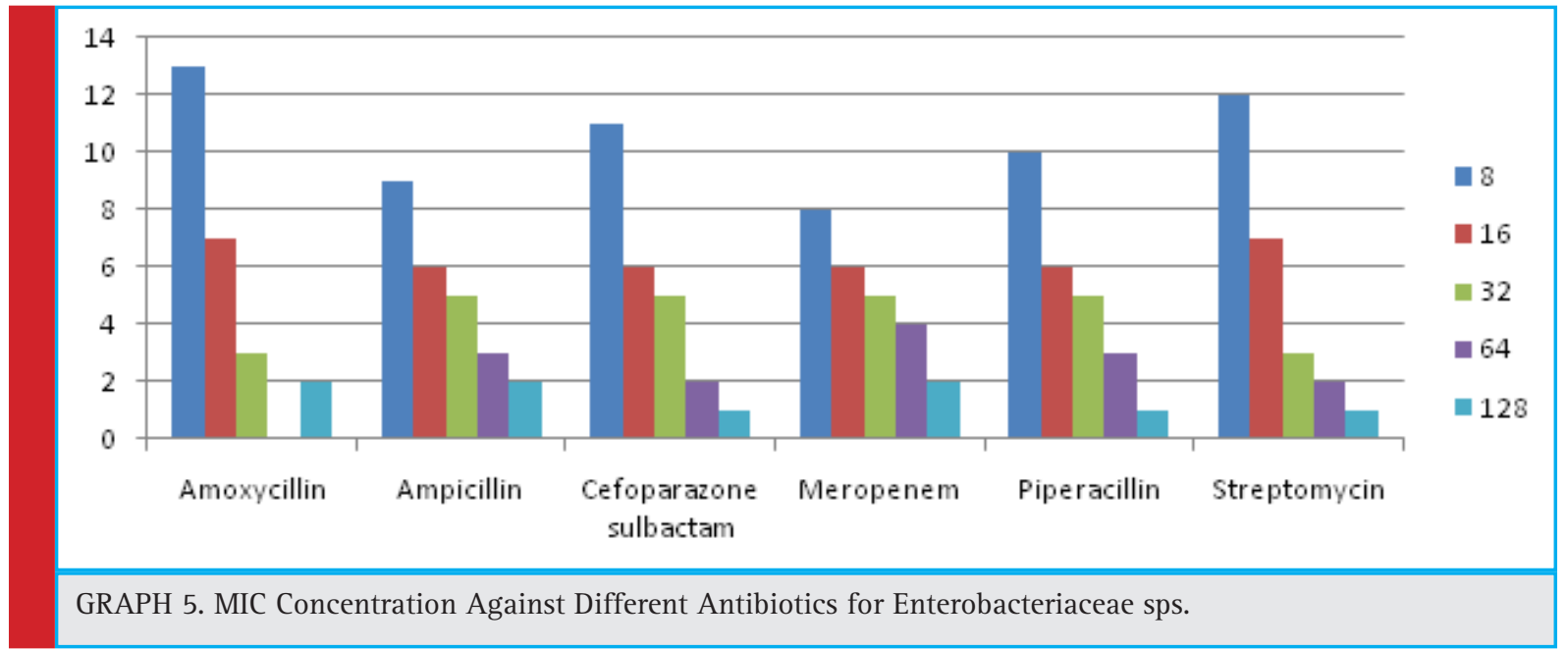




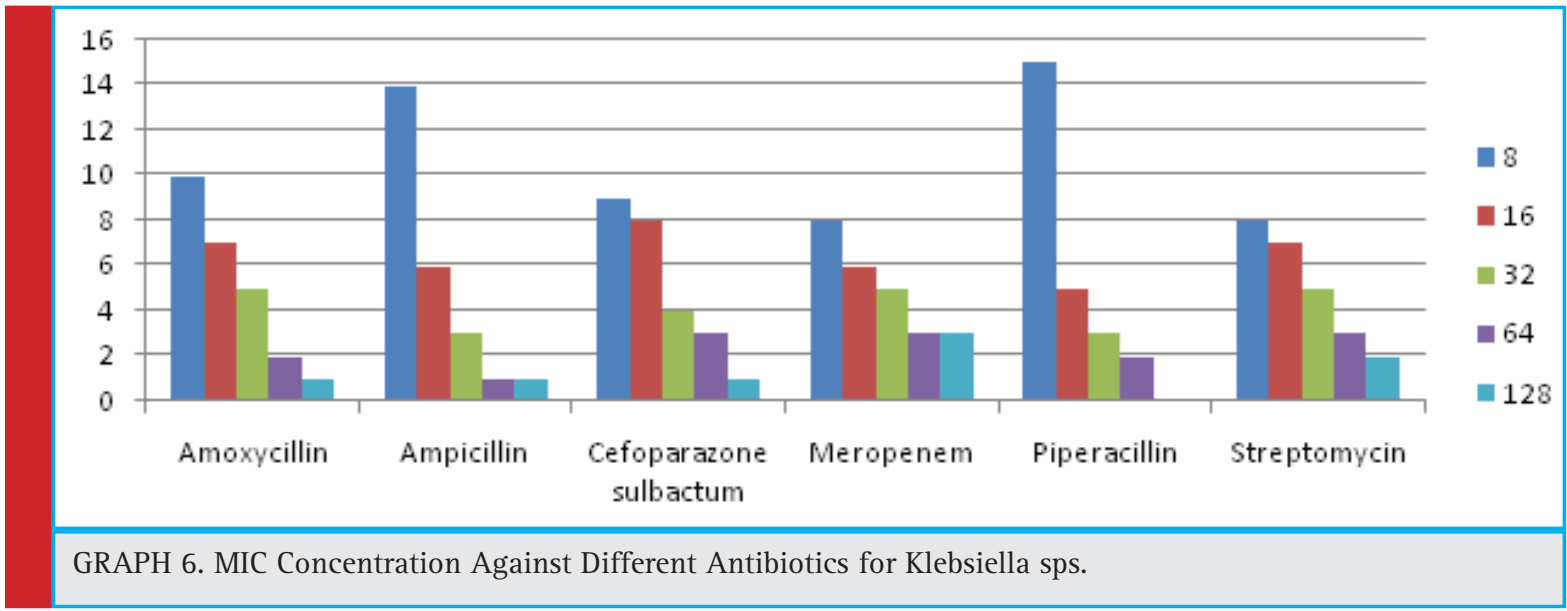

strains, but also in commensal bacteria (Luzzaro et al., 2001)

In the present study, the samples from different localities of Balawala were collected and total of 87 isolates were obtained from them and among these 50\% were $E$. coli, 25\% were Klebsiella spp., 15\% were Enterobacteriaceae spp., and 10\% were Proteus spp. The isolates were then identified on the basis of biochemical characteristics and the Klebsiella, E. coli, Proteus, Enterobacteria and Pseudomonas were isolated from the excreta of animals. Antibiotic resistance among the isolates was also evaluated using for antibiotics- amikacin, gentamicin, novabiocin, ofloxacin, ciprofloxacin, cephalexin, cefixime, amoxicillin, clotrimazole, trimethoprim, kanamycin, ampicillin, streptomycin, meropenem, piperacillin tazobactam and cefoparazone sulbactum.

In our study it has been seen that resistance was seen for novabiocin (50\%), cefixime (25\%), clotrimazole (15\%) and amoxicillin (10\%). It was also found to be sensitive for gentamicin, amikacin, kanamicin, trimethoprim, ciprofloxacin and ofloxacin. The MIC test was also conducted during this study those isolates are chosen for the MIC that showed more resistance efficacy. The MIC has been performed by chosing the different isolates in which following antibiotics was used viz amoxicillin, ampicillin, cefoparazone sulbactum, meropenem, piperacillin tazobactum and streptomycin. $50 \%$ of the isolates showed resistance among the antibiotic amoxicillin, ampicillin, streptomycin at different concentrations $(8 \mu \mathrm{g} / \mathrm{ml}, 16 \mu \mathrm{g} / \mathrm{ml}, 32 \mu \mathrm{g} / \mathrm{ml}, 64 \mu \mathrm{g} / \mathrm{ml}$ and $128 \mu \mathrm{g} / \mathrm{ml}$ ) and 50\% showed sensitivity against the antibiotic cefoparazone sulbactum, meropenem and piperacillin tazobactum. The high density of enteric pathogen and prevalence of multidrug resistant E. coli, Proteus and Kleibsiella in the fecal matter may pose severe public health risk.

\section{CONCLUSION}

In this study, we analysed the susceptibility pattern of different aminoglycosides in different locality of Bala-

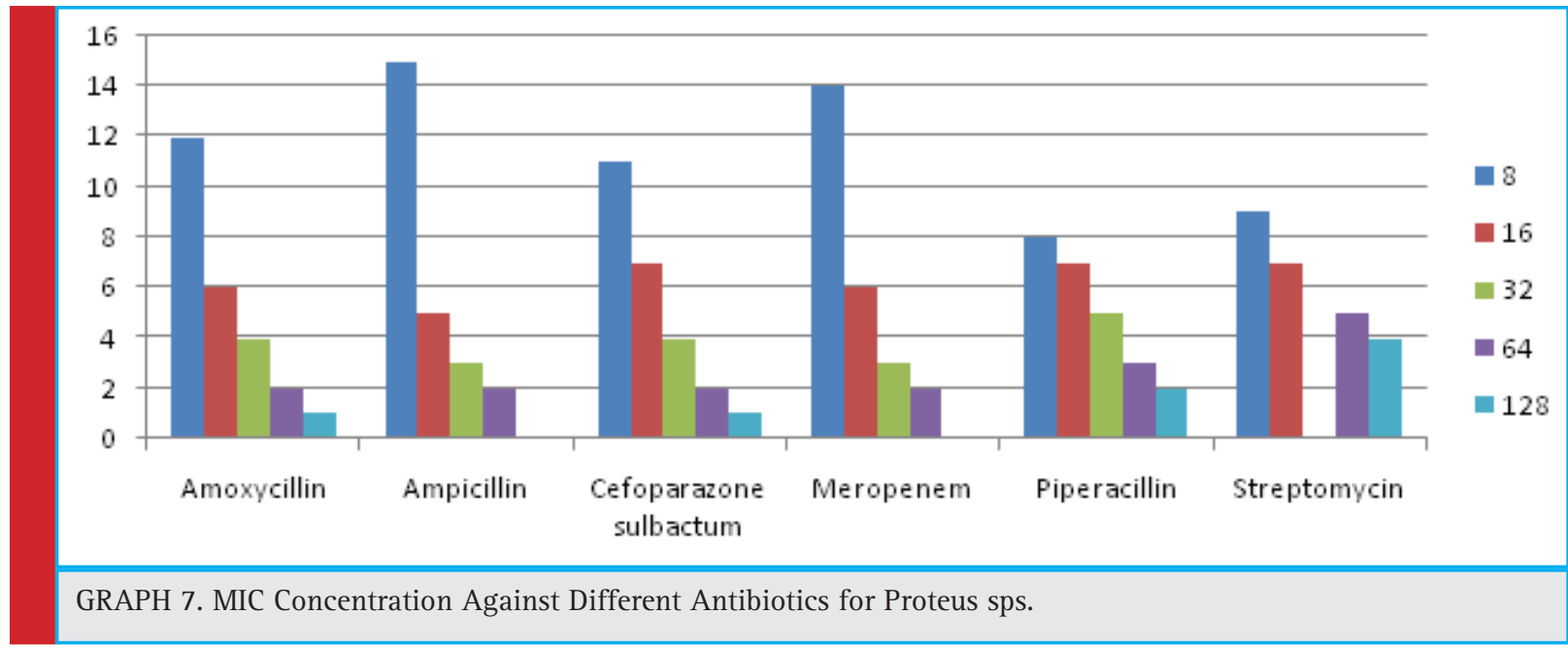

610 
wala, strain collections of E. coli, Klebsiella spp., Pseudomonas spp., Enterobacteriaceae spp. and Proteus spp. Enteric pathogens, which are of great concern since they are the most common causes of infection among humans and animals. Aminoglycosides represent an important class of antimicrobial agents. The prevalence of aminoglycoside resistance among Gram-negative bacteria in Dehradun is low, but an increased prevalence among clinical isolates of Escherichia coli has been observed during the last years. The most prevalent resistance mechanism is aminoglycoside modifying enzymes.

\section{REFERENCES}

Ahmed AA, Osman H, MAnsour AM, Musa HA, Ahmed AB, Karror Z, Hassan HS. (2000) Antimicrobial agent resistance in bacterial isolates from patients and diarrhea and urinary tract infection in the Sudan; Am J Trop Med Hyg.; 63 (5-6): 259-63.

Borrego JJ, Figueras MJ (1997) Microbiological quality of natural waters. Microbiologia 13:413-426

Bywater R, Deleryker H, Deroover E, Annode Jong, Mrion A, McConville M, Rowan T and Walters J (2004) A European survey of the antimicrobial susceptibility among zoonotic and commensal bacteria isolated from food producing animals, J. Antimicrob. Chemotherap. 54: 744-754.

Dancer SJ, et al. (1997) Isolation and characterization of coliforms from glacial ice and water in Canada's High Arctic. J Appl Bacteriol; 82: 597-609.

Datta N, Hughes VM (1983) Plasmids of the same Inc groups in enterobacteria before and after the medical use of antibiotics. Nature; 306: 616-627.

Ergin C \& Mutlu G. (1999) Clinical distribution and antibiotic resistance of Pseudomonas sps. Eastern journal of medicine 4 (2); 65-69.

Garcia DC, Trevisan AR, Botto L, Cervetto M, Sarubbi MA, Zorzopulos J (1989) An outbreak of multiply resistant Pseudomonas aeruginosa in a neonatal unit: plasmid pattern analysis. $J$ Hosp. Infect; 14: 99-105.

Gerding DN, Larson TA, Hughes RA, Weiler M, Shanholtzer C, Peterson LR (1990) Aminoglycoside resistance and aminoglycoside usage: ten years of experience in one hospital. Antimicrob Agents Chemother; 35: 1284-1290.
Hopkins JD, Flores A, Pilar-Pla M, Lester S, O’Brien TF (1991) Nosocomial spread of an amikacin resistance gene on both a mobilized, nonconjugative plasmid and a conjugative plasmid. Antimicrob Agents Chemother 35: 1605-1611.

Hryniewicz K, Szczypa K, Sulikowski K, Bettejewska K, Hryniewicz W (2001) Antibiotic susceptibility of bacterial strains isolated from urinary tract infections in Poland, J Antimicrob Chemother; 47(6): 773-80.

Kalita, S, Kandimalla, R, Sharma, KK, Kataki, AC, Deka, M and Kotoky, A (2016) Amoxicillin functionalized gold nanoparticles reverts MRSA resistance. Mater. Sci. Eng. C 61 720-727.

Khachatourians, G (1998) Agricultural use of antibiotics and the evolution and transfer of antibiotic-resistant bacteria. Canadian Medical Asso. J. 159: 1129-1136.

Larson TA, Garrett CR, Gerding DN (1986) Frequency of aminoglycoside 6'-N-acetyltransferase among Serratia species during increased use of amikacin in the hospital. Antimicrob Agents Chemother; 30: 176-178.

Levine JF, Maslow MJ, Leibowitz RE et al. (1985) Amikacinresistant Gram-negative bacilli: correlation of occurrence with amikacin use. J Infect Dis; 151: 295-300.

Luzzaro F, Perilli M, Amicosante G, et al. (2001) Properties of multidrug-resistant, ESBL-producing Proteus mirabilis isolates and possible role of beta-lactam/beta-lactamase inhibitor combinations. Int J Antimicrob Agents; 17 (2): 131-135.

Pelcezar MJ, Chan ECS, Krieg NR (1986) In: Microbiology. 5 th edition. Tata McGraw- Hill Publishing Company pp 598-614.

Schwarz, S and White, D (2005) Phenolic resistance. Frontiers in Antimicrob. Resistance. ASM press. 124-148.

Sharma, KK, Saikia, R, Kotoky, J, Kalita, JC and Das, J (2011) Evaluation of antidermatophytic activity of piper beetle, Allamanda cathertica and their combination: an in vitro and in vivo study. Int. J. PharmTech. Res. 3 644-651.

Shaw KJ, Rather PN, Hare RS, Miller GH (1993) Molecular genetics of aminoglycoside resistance genes and familial relationships of the aminoglycoside-modifying enzymes. Microbiol Rev.; 57: 138-163.

Shimizu K, Kumada T, Hsieh WC et al. (1985) Comparison of aminoglycoside resistance patterns in Japan, Formosa, and Korea, Chile, and the United States. Antimicrob Agents Chemothe, 28: 282-288. 